\title{
AVALIAÇÃO DA APRENDIZAGEM E INTERNACIONALIZAÇÃO DA EDUCAÇÃO: UMA ABORDAGEM PELA TECNICA DO WHITE PAPER
}

\author{
Ronier Pereira da Silva, Universidade Federal de Campina Grande (UFCG), \\ reinor.silva@gmail.com \\ Cristina Novikoff, Universidade federal de Campina Grande (UFCG), \\ cristinanovikoff@gmail.com
}

\section{RESUMO}

O presente estudo que é parte de uma monografia tem o intuito de apresentar alguns indícios, por meio da técnica White Paper, que as politicas transnacionais para educação sofrem influencias de uma logica econômica e podem distorcer as concepções de avaliação como um processo Didático- pedagógico na construção do conhecimento para simples medição de variáveis, assumindo assim um caráter negativo para os estudantes.

PALAVRAS-CHAVE: Avaliação de Aprendizagem 1; Politicas Transnacionais 2; White peper 3 .

\section{INTRODUÇÃO}

$\mathrm{Na}$ atualidade, no cenário mundial surgem novas forças de domínio geopolítico e econômico, a disputa pela hegemonia, antes pelo poderio militar, passa agora diretamente pela concorrência comercial, o que leva a diversas nações se organizarem em blocos econômicos no qual países se unem para fortalecer as relações comerciais, ampliando suas fronteiras e reduzindo obstáculos econômicos. Através dessa perspectiva liberalista os diversos chefes de estados do mundo vêm à educação como parte importante para o desenvolvimento e soberania do país.

Pensando em assegurar o padrão de qualidade da educação, os blocos econômicos constroem avaliações uniformizadas com base em politicas econômicas. No liberalismo o conceito de qualidade socialmente referenciada nos sistemas de ensino se assemelha ao conceito de qualidade comercial, tendo como parâmetro a eficiência, induzindo a produtividade, o conhecimento passa a ser produto, ao contrario de um processo de construção, e a avaliação usada para ranqueamento diferentemente de uma ferramenta didático-pedagógica. Todo o fator pedagógico converge para atender avaliações homogeneizadas 
Por meio de acordos de cooperação e troca de informações entre os países associados economicamente, a globalização difunde as politicas educacionais por todo globo podendo influenciar no currículo das instituições focando-os na busca por resultados. Para tanto as diversas formas de avaliações, se aplicada corretamente, são instrumentos importantes na construção do conhecimento uma vez que se utiliza de um contexto mais amplo para um diagnóstico do processo de aprendizagem eficaz.

Dessa forma, esse trabalho tem o objetivo de apresentar, por meio da técnica de white paper ${ }^{1}$, indícios que as politicas transnacionais para avaliações podem distorcer as concepções de avaliações como instrumentos didático-pedagógicos, uma vez que é meramente confundida com medição para classificação, e assim, consequentemente assumir um aspecto negativo.

\section{O DELINEAMENTO PELA TECNICA DO WHITE PEPER}

Das leituras relacionadas no âmbito das avaliações da aprendizagem no contexto da internacionalização da educação, surgiu esse artigo que foi elaborado a partir de uma analise das publicações cientificas de veículos, repositórios e revistas especializados na área com conceito Qualis A1, A2, B1 e B2 pela Capes, seguindo o delineamento utilizado pela técnica de White paper.

O "Qualis Periódicos” lista a classificação dos veículos científicos utilizados pelos Programas de Pós-Graduação para disseminar a produção científica. O conceito A1 é o nível máximo de referência em termos de qualidade, seguido em ordem decrescente pelos periódicos considerados A2; B1; B2; B3; B4; B5; C (BORGES e CALDERÓN, 2011).

A busca pelos artigos se deu por meio do banco de dados da Capes, o indexador SCIELO, e o Google Acadêmico, tendo como critério o interesse do autor e proximidade do seu objeto de pesquisa direcionada pelas palavras chaves: avaliação da aprendizagem, avaliação externa, concepções de avaliação, considerando o período de publicação entre 2010-2016. foram analisados 7 artigos que dialogam com alguns teóricos especialista da área.

O White Paper é um termo derivado do White book cuja definição do termo teve inicio na politica governamental tornando-se posteriormente uma ferramenta comum para apresentar produtos e inovações tecnológicas, trata-se de um documento persuasivo que geralmente descreve um problema e fornece uma solução (CERUTTI et al, 2011)

\footnotetext{
${ }^{1}$ Tradução livre : Papel Branco
} 
Segundo Rouse e Smith (2005) varias versões na internet afirmam que o formato surgiu na ultima década na Inglaterra para diferenciar relatórios de governo curtos dos longos, no qual que eram mais detalhados. Na tecnologia da informação, o White Paper é um artigo escrito por um designer para explicar a filosofia e operação de um produto em um determinado mercado ou contexto de tecnológico. No governo um White Paper é na maioria das vezes uma politica ou documento de posição.

O White paper é usado para educar seus leitores sobre uma questão especifica ou para explicar e promover uma metodologia característica (ROLOWCH, 2014). Como sendo um hibrido de artigo e material descritivo-publicitário contendo informações uteis, opiniões de especialistas e uma logica estabelecida da pesquisa, terce persuasivas mensagens corporativas (CERUTTI et al, 2011)

A escolha do delineamento desse artigo pelo método do White Peper se deu a partir da necessidade de suas características de informar e persuadir com fatos e evidencias concisas, um determinado público alvo, no nosso caso docentes e discentes do ensino superior, a refletirem sobre a avaliação da aprendizagem e sobre como a mesma sofre influencias de fatores externo como as politicas transnacionais.

\section{ENFOQUE SOBRE AVALIAÇÃO DA APRENDIZAGEM DIANTE DA INTERNACIONALIZAÇÃO DA EDUCAÇÃO}

A universidade tem como norma a internacionalização da função pesquisa, ancorada na autonomia do pesquisador. $\mathrm{O}$ ensino, principalmente o de graduação, tem um forte controle do estado, no caso brasileiro, desde o processo de autorização e reconhecimento de uma instituição, credenciamento de cursos, adequação às diretrizes curriculares dos cursos, implantação e execução do processo de avaliação até o reconhecimento de títulos e diplomas realizados no exterior. O formalismo e a dependência das políticas estatais dificultam a autonomia do ensino no contexto da internacionalização da educação superior (MOROSINI, 2006, p.108).

Nessa conjuntura de internacionalização da educação, Leite e Genro (2012) em seu artigo intitulado "Avaliação e internacionalização da Educação Superior: Quo vadis América Latina?" Tratam de questões sobre avaliação, acreditação e internacionalização das instituições de Educação Superior da América Latina e do Caribe. Elaboram hipóteses e 
apresentam evidencias da existência de um novo imperialismo, argumentando que os processos de avaliação e acreditação internacionais sustentam-se em bases liberais formadas por redes de agencias e atores do capitalismo no qual suas consequências ainda não foram explicitamente reveladas para as Instituições de Educação Superior (IES).

O Pensamento das autoras fica evidente no trecho:

Um novo imperialismo, na sua forma benevolente, está a se constituir tendo a Europa do Conhecimento como centro hegemônico e a América Latina como centro subordinado. O conhecimento uniformizado se estabelece através da avaliação e acreditação. A dominação política se estabelece pelo consentimento e adesão (2012, p. 780)

Ainda sob esse prisma, Siebiger (2011) analisa em "O processo de Bolonha e sua influencia na definição de espaços transnacionais de educação superior: A universidade brasileira em movimento" os possíveis impactos na reorganização de estruturas de educação superior europeia promovidas recentemente pelo processo de Bolonha e como essas reformas podem influenciar politicas e sistemas transnacionais de educação superior na América Latina no qual contexto o Brasil esta inserido.

Para tal, o autor argumenta que:

[...] iniciativas propostas de convergência dos sistemas de educação superior da Europa, América Latina e Caribe estabelecidas na Declaração de Florianópolis, o Tratado de Amizade Brasil-Portugal, as medidas prospectadas pelo MERCOSUL e a recente implementação de três instituições superiores - universidade federal da Integração LatinoAmericana (Unila), Universidade da Integração internacional da Lusofonia Afro-Brasileira (UniLAB) e universidade Federal da Integração Amazonica (Uniam) - seriam passos concretos em direção a construção de estruturas de educação superior na América Latina equivalentes e compatíveis com as previstas no processo de Bolonha.( 2011, p. 120)

Conforme os autores fornecem evidencias sobre as redes de influencias traçadas pela globalização, surge à preocupação das implicações praticas no ensino superior. Com realidades tão distintas entre países, a homogeneização da educação consegue alcançar as especificidades de cada contexto educacional?

Um sistema educacional comum de acordo com Lima et al (2008) sobre o tratado de Bolonha devera corresponder a uma entidade, associação ou agencia de avaliação que ficara responsável por acreditar e avaliar para construir uma garantia de qualidade da educação, resultando em avaliações tecnocrata, gerencial, quantitativa e estandardizada. É importante 
diante desses aspectos, analisar conceitos de qualidade que perneiam esse âmbito das avaliações e se correspondem às necessidades da episteme ${ }^{2}$.

Em seu estudo "Avaliação e qualidade do desenvolvimento profissional docente" Gatti (2014) aborda as diferentes perspectivas em processos avaliativos, levanta questionamento sobre o conceito de qualidade docente e discute pontos sobre o desenvolvimento profissional do docente, ao fim tratar de algumas formas avaliativas utilizadas e enfatiza que o modo de iniciar e implementar processos avaliativos requer posturas formativas tanto dos avaliadores quanto dos avaliados.

Gatti (2014, p.374) no tópico avaliação e qualidade do seu trabalho discorre que as avaliações são neutras, mas quando se trata de associa-las a politicas publicas suas finalidades evidenciam o papel institucional. $\mathrm{O}$ autor classifica a avaliação em dois grandes grupos: funcionalista-pragmatista que resumem a modelos somativos com base em pontuações com finalidade de alcançar critérios e metas utilizando o desempenho dos alunos em avaliações externas; e analítico-construtiva que mostram-se com foco explícito na valorização e desenvolvimento das pessoas com metodologias de caráter formativo por meio de processos que visam a compreensão por reflexão compartilhada.

O sistema de acreditação para qualificar os sistemas educacionais perante politicas transnacionais usam as avaliações externa como critério classificativo em função do alcance de metas estipuladas, é esse tipo de avaliação a qual Gatti classificou como funcionalistapragmatista. Diante desses fatos surge um importante o questionamento: A qualidade ofertada nos selos dessas agencias avaliadoras é socialmente referenciada?

No ensaio "Dicotomias conceituais da avaliação da educação superior" da autora Pfeifer (2012) resgata, por meio de diversas literaturas especializadas, concepções que envolvem a Avaliação no âmbito das Políticas para a Educação Superior explicitando as conceituações dicotômicas encontradas, dentre elas cita: Qualidade Social x Qualidade Eficiência, Avaliação Quantitativa x Avaliação Qualitativa, Avaliação de Processo x Avaliação de Produto, Avaliação Global x Avaliação Pontual, Avaliação Contextualizada x Avaliação Descontextualizada, Avaliação Externa x Avaliação Interna, Avaliação Formativa x Avaliação Punitiva.

${ }^{2} \mathrm{Na}$ filosofia grega, esp. no platonismo, o conhecimento verdadeiro, de natureza científica, em oposição à opinião infundada ou irrefletida 
Pfeifer (2012, p.362) finaliza afirmando que o processo avaliativo pode estar na mão do que ela denomina como estado avaliador ou agencias avaliadoras, esse estado avaliador é o responsável pela implementação dos processos e mecanismos de avaliação por instituições governamentais, mas que é comum cada vez mais agências avaliadoras de caráter transfronteiriço ligadas a organismos multilaterais como UNESCO, BIRD, $O C D E^{3}$ que concedem selos de qualidade a instituições e programas educacionais.

As politicas transnacionais oriundas de instituições e agências econômicas sujeitam as universidades a logica empresarial de produtivismo, e essa relação acaba interferindo diretamente no processo de ensino-aprendizagem na sala de aula e por muitas vezes nas concepções de avaliação de aprendizagem dos professores e ate mesmo dos próprios alunos. As avaliações da aprendizagem perante esse contexto de politicas transnacionais suprem as necessidades dos processos cognitivos dos alunos?

No artigo "A avaliação no ensino superior privado como tecnologia neoliberal de regulação" Nunes e Neira (2015) tentam analisar como as práticas avaliativas presentes no currículo de Licenciatura em uma instituição privada de Ensino Superior subjetivam sujeitos em meio à cultura empresarial mediante alusões à eficiência, flexibilidade e mérito. Segue comentando que fator econômico de mercado influencia nas avaliações educacionais e estas por sua vez são utilizadas como aparato de manutenção da hegemonia da atual forma de organização social baseada no neoliberalismo. O artigo mostra a visão de uma logica econômica que preconiza a instituição como empresa que valoriza o controle de qualidade (eficiência) para manter-se na concorrência do mercado.

Pacheco (2009, p.109) diz que a globalização reforça os fundamentos da teoria do capital humano, em que reconhece a educação como processo de formação social, direcionada para mercados competitivos, onde requer que as organizações educativas respondam a desafios imediatos do mundo económico.

Em conformidade com Pacheco, Neira e Nunes (2015) afirmam que:

As práticas avaliativas institucionais analisadas destacam a emergência de um Estado avaliador que regula as identidades afeitas ao novo modelo que, cada vez mais, faz dos assuntos de políticas regionais e globais um tema de

\footnotetext{
${ }^{3}$ Organizações das Nações Unidas para a Educação, a Ciência e a Cultura.

Banco Internacional Para Reconstrução E Desenvolvimento

Organização para a Cooperação e Desenvolvimento Económico
} 
interesse comercial internacional. Pode-se dizer que suas metas e efeitos visam garantir a adequação do profissional que favorecerá o desenvolvimento econômico da nação, amarrando-o no enredo dos resultados, logo na nova função do Estado ( p.396.)

A avaliação externa tem certo destaque nas politicas educacionais uma vez que serve como um instrumento de regulação das instituições ao constatar se as metas propostas chegaram ao seu objetivo ou não. Essas avaliações em larga escala têm contribuições significativas para aprendizagem, se possuem, quais são?

Correia et al (2015) faz um dossiê de diferentes pesquisas e estudos em seu trabalho "Para onde caminham as atuais avaliações educacionais?" composto de sete artigos de professores do Brasil, Itália, Irlanda, Finlândia, Portugal, e uma entrevista com o Prof. John MacBeath, da Inglaterra, mostrando importantes reflexões criticas a respeito dos paradigmas que perneia a avaliação em larga escala, em estratégia única para medir o desempenho dos alunos em todos os níveis de ensino. $\mathrm{O}$ autor chega à conclusão que apesar de reconhecerem mais críticas do que pontos positivos na literatura nacional e internacional, os autores se colocam de forma crítica, acreditando, no entanto, que tais avaliações ainda podem contribuir ao conhecimento disponível e que se utilizada adequadamente possivelmente poderá garantir o direito de educação a todos. E para serem bem-sucedidas as avaliações exigem uma participação consciente de todos os envolvidos uma vez que é um processo complexo levando em consideração questões éticas uma vez que suas incompatibilidades com o cotidiano levam a corrupção na educação.

Chuieire $(2008$, p.52) diz que na condição de avaliador do processo de ensino e aprendizagem, o professor interpreta e atribui sentidos e significados à avaliação, produzindo conhecimentos e representações a respeito da avaliação e acerca de seu papel como avaliador, com base em suas próprias concepções, vivências e conhecimentos.

Entre avaliação e aprendizagem existem vários níveis de relacionamento. Diversificados estudos abordam a avaliação da aprendizagem na educação superior sugerindo a existência de uma relação intimamente ligada entre as práticas de avaliação aplicadas pelos professores e os diferentes níveis de desenvolvimento dos estudantes no decorrer da graduação. Essas práticas podem influenciar, por exemplo, a natureza das experiências de aprendizagem experimentada pelos alunos, como eles se envolvem com os estudos, que 
conhecimentos são importantes e como se veem no ensino universitário (GARCIA, 2009, p.250).

Saber como os estudantes experienciam as avaliações é de suma importância, visto que esta essa pratica didática esta cada vez mais inclusa dentro do contexto social do processo de internacionalização da educação como mecanismo de analise da qualidade. Em "Avaliação no ensino superior: Concepções múltiplas de estudantes brasileiros" Matos et al. (2013) analisa as concepções dos alunos do ensino superior por meio do questionário Students' Conceptions of Assessment (SCoA) onde foi adaptado para realidade da amostra pesquisada em uma instituições publica e uma privada. Usando um cruzamento de dados complexo através de programas e softweres que fazem frequência e porcentagem das respostas dos alunos ao questionário, o autor chega ao resultado que "a avaliação ajuda a melhorar o ensino-aprendizagem, torna alunos e escolas responsáveis e não é algo a ser ignorado. Mas a avaliação também pode ser ruim ou injusta e quase não tem um impacto emocionalmente positivo nos alunos" encerra afirmando que é importante o estudo sob como os alunos veem a avaliação e a pertinência de se conhecer as concepções também de gestores e professores.

Para Pereira e Flores (2012, p. 535) Avaliar a aprendizagem de um estudante é, talvez, a parte mais emocional da educação, pois, além da exigência a nível intelectual, pode em alguns casos, ser socialmente perturbadora e criar divisões nos estudantes. A avaliar é uma ação complexa que leva consigo, imbricado em sua pratica, um conjunto de relações, concepções advindas de vivencias, e cargas emocionais. Falando em avaliação, nos resta refletir, será que levamos em consideração esses fatores quando pensamos em avaliar?

Encerramos usando as palavras de Vianna (2003, p.45) "As avaliações são realizadas para diferentes fins destacando-se, inicialmente, como uma de suas prioridades, a identificação de problemas de aprendizagem, com o fito evidente de imediata superação do quadro apresentado, entretanto a realidade é bem diversa do imaginado e pretendido".

\section{CONSIDERAÇÕES FINAIS}

A avaliação da aprendizagem da forma que é concebida pelos estudantes assume algumas vezes um aspecto negativo quando na perspectiva clara de escalonamento ou classificação através da atribuição de uma nota/pontuação. Essa concepção retrógada de 
avaliação é reforçada aos docentes pela representação social do contexto atual da educação que é orientado por fatores econômicos provenientes das politicas transnacionais de acordo com a internacionalização da educação.

Se aplicada de forma correta em uma perspectiva formativa a avaliação de aprendizagem é uma excelente ferramenta de diagnostico para a construção de um conhecimento pertinente, sendo assim se faz necessário, pesquisas aprofundadas sobre os fatores externos que podem afetar a avaliação de aprendizagem e estimular a reflexão sobre as diversas concepções de avaliação, metodologias, bem com suas implicações para um melhor processo de ensino-aprendizagem, por meio da formação continuada para docentes.

Para Cerutti et al (2011, p.72) aprofundar a compreensão sobre a complexidade de variáveis que constituem o processo de avaliação é necessário, bem com buscar tanto a qualificação dos instrumentos já criados, quanto a ampliação de instrumentos e índices que possam dar conta das dimensões mais subjetivas e qualitativas, abarcando as particularidades regionais, contextuais e culturais de cada realidade, na Política e no Sistema de Avaliação da Educação Superior Brasileira.

A técnica do White paper possibilitou tecer uma rede de argumentos por meio do dialogo entre estudos realizados e alguns teóricos ligando alguns "indícios" na tentativa convencer o leitor a "comprar uma ideia" no nosso caso, a afirmativa que: As politicas transnacionais para avaliações podem distorcer as concepções de avaliações da aprendizagem. No intuito de estimular pesquisa e/ou reflexões direcionada a certa área de interesse, o delineamento pelo método do White paper passa a ser uma ferramenta útil de persuasão. 
EVALUATION OF LEARNING AND INTERNATIONALIZATION OF EDUCATION: A FOCUS ON WHITE PAPER TECHNIQUE

\begin{abstract}
The present study, which is part of a monograph, intends to present some evidence, through the White Paper technique, that transnational policies for education are influenced by an economic logic and can distort the conceptions of evaluation as a Didactic-pedagogical process in Construction of knowledge for simple measurement of variables, thus assuming a negative character for students.
\end{abstract}

KEYWORDS: Learning Assessment 1; Transnational Policy 2; White paper 3.

EVALUACIÓN DEL APRENDIZAJE E INTERNACIONALIZACIÓN DE LA EDUCACIÓN: UN ENFOQUE POR LA TECNICA DEL WHITE PAPER

\title{
RESUMEN
}

El presente estudio que es parte de una monografía tiene el propósito de presentar algunos indicios, por medio de la técnica White Paper, que las políticas transnacionales para la educación sufren influencias de una lógica económica y pueden distorsionar las concepciones de evaluación como un proceso Didáctico-pedagógico La construcción del conocimiento para la simple medición de variables, asumiendo así un carácter negativo para los estudiantes.

PALABRAS CLAVE: Evaluación de Aprendizaje 1; Política Transnacional 2; White peper 3 .

\section{REFERÊNCIAS BIBLIOGRÁFICAS}

BORGES, R. M.; CALDERÓN A. I. Avaliação educacional: o estado do conhecimento da Revista Ensaio: Avaliação e Políticas Públicas em Educação (1993-2008). Ensaio: aval. pol. públ. Educ., Rio de Janeiro, v. 19, n. 70, p. 42-56, jan./mar. 2011.

CERUTTI, E. et al. Avaliação da Educação Superior Brasileira: diálogos mediados pelo white paper. Revista Educação por Escrito - PUCRS, v.2, n.1, jun. 2011. 
CHUIEIRE, M. S. F. Concepções sobre a avaliação escolar. Estudos em Avaliação Educacional, v. 19, n. 39, p. 49-64, 2008.

CORREIA, J. A. A. V.; ARELARO, L.R.G.; FREITAS, L.C. Para onde caminham as atuais avaliações educacionais? Educ. Pesqui., São Paulo, v. 41, n. especial, p. 1275-1281, dez., 2015

FREITAS; A. A. S. M. Avaliação da educação superior no Brasil e Portugal homogeneização ou diferenciação? Avaliação, Campinas; Sorocaba, SP, v. 17, n. 1, p. 119-136, mar. 2012. GARCIA, J. Avaliação e aprendizagem na educação superior. Estudos em Avaliação Educacional, v. 20, n. 43, p. 201-213, 2009.

GATTI, B. A. Avaliação e qualidade do desenvolvimento profissional docente. Avaliação, Campinas; Sorocaba, SP, v. 19, n. 2, p. 373-384, jul. 2014.

LEITE, D.; GENRO, M. E. H. Avaliação e internacionalização da educação superior: Quo vadis América Latina. Avaliação, Campinas, v. 17, n. 3, 2012.

LIMA, L. C. et al. O processo de Bolonha, a avaliação da educação superior e algumas considerações sobre a Universidade Nova. Avaliação, Campinas, v. 13, n. 1, p. 7-36, 2008. MATOS; D. A. S. et al. Avaliação no ensino superior: Concepções múltiplas de estudantes brasileiros. Est. Aval. Educ., São Paulo, v. 24, n. 54, p. 172-193, jan./abr. 2013

MOROSINI, M. C. Estado do conhecimento sobre internacionalização da educação superior Conceitos e práticas. Educar em revista, n. 28, p. 107-124, 2006.

NUNES; M. L. F. NEIRA; M. G. A avaliação no ensino superior privado como tecnologia neoliberal de regulação. Avaliação, Campinas; Sorocaba, SP, v. 20, n. 2, p. 377-399, jul. 2015.

PACHECO; J. A. Processos e práticas de educação e formação. Para uma análise da realidade portuguesa em contextos de globalização. Revista Portuguesa de Educação, v.22 n.1, p. 105143. 2009

PEREIRA, D. R.; FLORES, M. A. Percepções dos estudantes universitários sobre a avaliação das aprendizagens: um estudo exploratório. Avaliação: Revista da Avaliação da Educação Superior, v. 17, n. 2, 2012.

PFEIFER, M. Dicotomias conceituais da avaliação da educação superior. Avaliação: Revista da Avaliação da Educação Superior, v. 17, n. 2, 2012. 
ROLOWCH, L. whats is a whitepaper? jun. 2014. disponivel em:

<https://blog.hubspot.com/marketing/what-is-whitepaper-faqs $>$ acesso em 12 de junho de 2017.

ROUSE, M.; SMITH T.D. Definicion White paper. Set. 2005. Disponivel em: $<$ http://searchmicroservices.techtarget.com/definition/white-paper >acesso em 12 de junho de 2017

SIEBIGER; R. H. O processo de Bolonha e sua influencia na definição de espaços transnacionais de educação superior: A universidade brasileira em movimento. Revista da faculdade de educação. Ano IX n 15 Jan/ Jun 2011.

VIANNA, H. M. Avaliações nacionais em larga escala: análises e propostas. Estudos em avaliação educacional, n. 27, p. 41-76, 2003. 